\title{
Diabetes Distress in Males and Females with Type 1 Diabetes in Adolescence and Emerging
}

\section{Adulthood}

Lašaitė $L^{1}$, Dobrovolskienė $\mathrm{R}^{2}$, Danyte $\mathrm{E}^{1}$, Stankutė $\mathrm{I}^{2}$, Ražanskaitė-Virbickienè $\mathrm{D}^{1}$, Schwitzgebel $\mathrm{V}^{3,4}$, Marčiulionytė $\mathrm{D}^{1}$, Verkauskienė $\mathrm{R}^{1}$

${ }^{1}$ Institute of Endocrinology, Lithuanian University of Health Sciences, Kaunas, Lithuania

${ }^{2}$ Department of Endocrinology, Hospital of Lithuanian University of Health Sciences Kauno Klinikos, Kaunas, Lithuania

${ }^{3}$ Department of Child and Adolescent, University Hospital of Geneva, Geneva, Switzerland

${ }^{4}$ Diabetes Center, Faculty of Medicine, University of Geneva, Geneva, Switzerland

\section{Abstract}

Background. Age and gender are important factors in the adjustment and psychological well-being of patients with chronic physical illness.

Aim: to explore the gender and age differences in diabetes distress between adolescents and emerging adults with type 1 diabetes (T1D).

Subjects and Methods. Diabetes distress was compared in 255 adolescents and 283 emerging adults with T1D using Problem Areas in Diabetes Scale.

Results. High diabetes distress level was found in $22.8 \%$ of participants.

Lack of confidence in self-care (6.0 vs 3.0, $\mathrm{p}=0.002)$, negative emotional consequences ( $10.0 \mathrm{vs}$ $6.0, \mathrm{p}=0.004)$ and overall score $(18.75$ vs. $11.25, \mathrm{p}=0.002)$ were higher in adult than in adolescent males, when adjusted for age at T1D onset. Negative emotional consequences (13.0 vs 10.0, $\mathrm{p}=0.005)$ and overall score ( 25.0 vs. $20.0, \mathrm{p}=0.016)$ were higher in adult compared to adolescent females, when adjusted for age at T1D onset. 
Lack of confidence in self-care (6.0 vs 3.0, p=0.002), negative emotional consequences (10.0 vs $6.0, \mathrm{p}=0.015)$ and overall score (20.0 vs $11.2, \mathrm{p}=0.005)$ were higher in adolescent females compared to males, when adjusted for age at T1D onset. Negative emotional consequences score was higher in adult females compared to males (13.0 vs $10.0, \mathrm{p}=0.029)$, when adjusted for age at T1D onset. In conclusion, our findings show that patients with T1D have greater burden of diabetes distress in emerging adulthood than in adolescence and add to evidence suggesting the importance of addressing diabetes distress in clinical care and the necessity of wider picture beyond the physical manifestation of diabetes to be taken into consideration.

Key words: diabetes distress, type 1 diabetes, adolescence, emerging adulthood, gender specific differences

\section{Introduction}

Distress in medical patients is often regarded as a normal response to the burden of diagnosis and treatment, discomforting symptoms and negative social implications. Chronic illness challenges patients' habitual coping strategies, with most eventually reaching good psychological adjustment, but for about $30 \%$ the adjustment phase is longlasting or unsuccessful (de Ridder et al., 2008). Patients with type 1 diabetes (T1D) can be seriously burdened by the chronic nature of this disease which results in diabetes-related emotional distress, impairments of emotional state and reduced quality of life (Rubin \& Peyrot, 1999). The emotional and behavioral challenges generated by diabetes and its management have been labeled " diabetes distress" (Fisher et al., 2015).

Depression and diabetes distress are both prevalent in the individuals with T1D (Northam et al., 2005). Depressive disorder is related to but distinct from diabetes distress. Many patients with high levels of depressive affect are really experiencing diabetes distress, not depression (Fisher et al., 2007). Diabetes distress is defined as an emotional response towards 
adverse or unpleasant stressors related to diabetes, whereas the definition of depression is based solely on a count of symptoms, irrespective of cause or context (Snoek et al., 2015). It was confirmed that diabetes-specific distress is a common condition that often includes high levels of negative affect, and is linked to poor behavioural disease management (Fisher et al., 2008).

Age and gender are important factors that moderate the impact of chronic physical illness on patient's adjustment and psychological well-being. In childhood boys with chronic physical illnesses are more likely than girls to display behavioral and adjustment problems (Gortmaker et al., 1990). Adolescent girls with T1D are more distressed by their diabetes, experiencing lower self-esteem, more depressive symptoms (Luyckx \& Seiffge-Krenke, 2009). Adult males with diabetes are less worried than females about long-term complications and hypoglycaemia, but more troubled by the limitation of personal freedom caused by diabetes (Gåfvels et al., 1993).

Adolescence is a difficult time for patients with T1D. Glycemic control and treatment adherence at the period of adolescence often deteriorate (Mann \& Johnston, 1982) and the risk of developing long-term complications seems to accelerate (Schultz et al., 1999). Adolescence is a period in development marked by significant biological, psychological and social changes (Holmbeck et al., 2006). Adolescents face multiple challenges and transitions, including puberty, changes in school, investment in peer and romantic relationships, and shifts in relationships with family (Graber, 2004). Each of these transitions and challenges has the potential to become sources of stress and to increase over the course of the adolescence (Byrne et al., 2007). In adolsecents with T1D, both cross-sectional and longitudinal studies have found a relationship of exposure to stressful life events with diminished glycemic control (Delamater et al., 1987; Helgeson et al., 2010). Increase in stressful life events is associated with increase in depression, anxiety, low self-esteem, and behavioral problems (Byrne et al., 2007; Johnson et al., 2002), and the presence of depressive symptoms or depression is an amplifier for diabetes-related distress (Hermanns et al., 2006). 
Emerging adulthood is a period of development between the ages of 18 and 25 . During this period youth explore possibilities in the areas of work and love and make choices that will define themselves as adults (Arnett, 2000). The majority of youth graduate from high school and go on to further their education or enter the labor force. From a relationship perspective, emerging adults separate from their families of origin and form attachments to peers, including romantic partners. It is a time of life when different directions remain possible and when the scope of independent exploration of life's possibilities is greater than it will be at any other period of the life course (Arnett, 2000). Emerging adulthood also is the period of development that is associated with the highest rate of risk behaviors (including alcohol and/or drug usage, unprotective sex, driving while intoxicated and so on) because of the increased freedom at this period of life (Arnett, 2000). There is some evidence that depressive symptoms peak in emerging adulthood (Kessler et al., 2004) and reports of stress are higher during this period than any other point in the lifespan (Stone et al., 2010). So, emerging adulthood is a period associated with increased oportunities, as well as increased risk and instability (Luecken et al., 2010; Arnett, 2007). The fluctuations that occure in roles, relationships, and living arrangements during emerging adulthood, even if positive, may be stressful. The stress associated with emerging adulthood could be effectively managed by high levels of self-esteem, mastery, optimism (Helgeson et al., 2014). The challenges of emerging adulthood may be even more stressful for those with T1D. Emerging adults with T1D are more likely than those without diabetes to suffer from depressive symptoms (Gendelman et al., 2009). People with T1D, especially females, are at increased risk for eating disorders compared to those without diabetes (Jones et al., 2000). Disturbed eating behavior is linked to diabetes-related complications (Rydall et al., 1997). It is possible, that in many adults with T1D diagnosed in childhood, diabetes distress and other psychological problems may develop with the compounded burden of years, or even decades, of disease management (Wolpert \& Anderson, 2001). 
To date, diabetes distress related issues are mainly examined in subjects with type 2 diabetes (T2D). Clinical research on diabetes distress with T2D, however, has not been matched by similar studies with T1D patients, who present with very different disease-related challenges and experiences (Fisher et al., 2015). Data on diabetes distress in T1D and what are diabetes distress possible peculiarities related to gender and age in T1D is very scarce.

The aim of the study was to explore the gender and age differences in diabetes distress between adolescents and emerging adults with type 1diabetes.

\section{Subjects and Methods}

\section{1. Subjects}

The cross sectional population-based study was conducted in a single research center as a part of joint Lithuanian-Swiss project "Genetic Diabetes in Lithuania". Patients who were younger than 25 years old at the time of the project beginning were recruited from the T1D registry in Lithuania. The total Lithuanian-Swiss project "Genetic Diabetes in Lithuania" cohort consisted of 1209 subjects covering all pediatric patients $(<18$ years, $n=860)$ and adult patients between 18 and 25 years old $(n=349)$ diagnosed with T1D in Lithuania who agreed to participate in the project $(70 \%$ of all adult patients between 18 and 25 years old agreed to participate).

Of all recruited to the total Lithuanian-Swiss project "Genetic Diabetes in Lithuania" participants, 613 (who at the time of the study beginning were of the age between 14 and 25 years) were asked to fill-in the Problem Areas in Diabetes (PAID) questionnaire. Of them, 538 (87.7\%) (258 males and 280 females) agreed and the data of the filled questionnaires were analysed in this study. The group of 75 patients who did not agree to fill-in the PAID questionnaire did not differ in terms of T1D duration, age at T1D onset and HbA1c level.

For the further analysis, study participants were stratified by age: 255 adolescents (123 males and 132 females, age $14-\leq 18$ years) and 283 emerging adults (135 males and 148 females, 
age $18-25$ years). Stratification of participants into 2 groups by age was according to Joint WHO/UNICEF Statement that adult person is older than 18 years old (WHO, 1989).

The data on gender, social status (only for adult patients) and insulin delivery method (insulin pumps or multiple daily injections) is presented in Table 1. Of 255 adolescent participants, $84(32.9 \%)$ were using insulin pumps, and 171 (67.1\%) were using multiple daily injections (MDI). Of 283 adult participants, 51 (18.1\%) were using insulin pumps, and 232 (81.9\%) were using MDI. Of 283 adult study participants, 97 (34.3\%) had lower than university education, and the rest had graduated university or were still studying there; 116 (40.9\%) were employed; 215 (75.9\%) were single, $62(21.9 \%)$ were married or cohabiting, and $6(2.2 \%)$ were divorced or separated.

Glycated haemoglobin (HbA1c) level was measured by UniCel DxC 800 Synchron system (Beckman Coulter, USA). The normal cut-off values of HbA1c were 4- 6\% (20 mmol/mol $42 \mathrm{mmol} / \mathrm{mol})$.

The study was approved by Lithuanian National Ethical Committee (No. BE-25/2013) and written informed consent was obtained from all study participants and their parents or official care-givers. The investigation was carried out in accordance with the Declaration of Helsinki.

\section{2. Psychological Assessment}

Problem Areas in Diabetes (PAID) scale was used for evaluation of diabetes distress of the participants (Polonsky et al., 1995; Welch et al., 1997). The PAID comprises 20 items assessing diabetes-related problems. Respondents rate the severity of each problem on a five-point Likert scale $(0$ - 'not a problem' to 4 - 'serious problem'). Summing all item scores and multiplying by 1.25 results in an overall PAID score, ranging from 0 to 100 . Higher scores indicate more severe distress. An overall score equal or higher than 40 was proposed as the cut-off criterion for screening purposes, suggesting clinical distress (Snoek et al., 2015). 
The results of a factor analysis in our study (see the "Results" section) were similar to that of the study by Miller \& Elasy (Miller \& Elasy, 2008) and confirmed 2 subdimensions for the PAID, with 5 items in the first subscale and 15 items in the second subscale. Similarly to Miller \& Elasy (Miller \& Elasy, 2008) and according to our results of factor analysis, for the further analysis of the data we used two subscales of the PAID : 1) Lack of Confidence in Self-Care Subscale, representing lack of confidence and concerns about diet, injections, physical activity, regimen, medical care and other diabetes-related items (5 items), and 2) Negative Emotional Consequences Subscale, representing negative emotions related to living with diabetes, feeling worried or overwhelmed by diabetes (15 items). Higher scores of a subscale indicate more severe distress of certain aspect.

\section{3. Statistical Analyses}

Analyses were performed using SPSS 22.0 software. After stratification for age and gender, according to Kolmogorov-Smirnov test, not all variables in different groups were normally distributed, so the differences between means in the groups were calculated using Mann-Whitney test. The values are given as median and quartiles (25-75 percentiles). Correlations between the study variables were calculated using Pearson test. The limit of significance was defined as a twosided p-value lower than 0.05 .

We performed factor analysis to examine the internal structure of the PAID. Both a scree plot and a minimum eigenvalue of 1.5 were utilized to guide extracting factors. Orthogonal and oblique rotations were explored to best approximate simple structure when extracting more than one factor. Item loadings of 0.4 or greater were the criterion used to guide interpretation of rotated factor loadings. Reliability was assessed by Cronbach's coefficient alpha: for internal consistency testing we accepted an alpha of 0.75 or greater. 


\section{Results}

Lithuanian translation of the PAID showed high internal consistency (Cronbach's alpha $=0.927)$. Conducting a factor analysis, principal component analysis resulted in 2 factors with eigenvalues of 3.3 and 6.2 which accounted for $16.4 \%$ and $30.9 \%$ of the variance, respectively, and with good internal consistency (Factor 1 Cronbach's alpha $=0.799$; Factor 2 Cronbach's alpha $=0.908)$. The scree plot also showed two components. Orthogonal rotations best approximated simple structure for these 2 factors: 5 loaded on the first factor ("Feeling discouraged with your diabetes treatment plan?”, "Not accepting your diabetes?", "Feeling unsatisfied with your diabetes physician?", "Feeling that diabetes is taking too much of your mental and physical energy every day?", "Feeling alone with your diabetes?") and the rest 15 loaded on the second factor. Similarly to the study by Miller \& Elasy (Miller \& Elasy, 2008), items loaded on the first factor were interpreted as "Lack of Confidence in Self-Care" Subscale and those loading on the second factor as "Negative Emotional Consequences" Subscale.

Correlations of the PAID overall score to Lack of Confidence in Self-Care Subscale $(\mathrm{r}=0.941, \mathrm{p}<0.001)$ and to Negative Emotional Consequences Subscale $(\mathrm{r}=0.981, \mathrm{p}<0.001)$ as well as between both subscales $(\mathrm{r}=0.857, \mathrm{p}<0.001)$ were high and significant.

Of our study sample, 123 (22.8\%) T1D patients (44 (17.2\%) adolescents (18 males and 26 females) and 79 (27.9\%) adults (31 males and 48 females)) reported diabetes distress overall scores over the cut-off limit, equal or higher than 40 on the PAID scale (Snoek et al., 2015), suggesting clinical distress.

Differences of age, age at diabetes onset, diabetes duration, HbA1c level (as a measure of diabetes glycaemic control), diabetes-related distress subscales and overall score in adolescent and adult T1D patients by age groups and gender are presented in Table 2 .

Lack of confidence in self-care and negative emotional consequences levels were higher in adult males compared to adolescent, as well as the PAID overall score, when adjusted for 
age at T1D onset. Negative emotional consequences and overall score were higher in adult compared to adolescent females, when adjusted for age at T1D onset (Table 2).

Comparing by gender groups and adjusting for age at the disease onset, significantly higher diabetes distress levels in subscales of lack of confidence in self-care and negative emotional consequences as well as in the PAID overall score were found in adolescent T1D females than in males. In adult T1D patients negative emotional consequences score was significantly higher in females than in males (Table 2).

Comparing by insulin injection method (insulin pumps vs multiple daily injections) groups, in adolescent and in adult patients no significant differences were found neither in $\mathrm{HbA} 1 \mathrm{c}$ levels, nor in diabetes distress evaluations (Lack of Confidence in Self-care subscale, Emotional Consequences subscale, PAID overall score).

In emerging adults with T1D no differences in diabetes distress subscales and overall score were detected comparing by education status, employment and marital status groups. HbA1c level was significantly higher in adult T1D patients with lower than university education than in patients who already graduated university or were still studying there, but no difference in HbA1c level was detected comparing in different employment and marital status groups.

Correlation analyses (Table 3) revealed that diabetes distress was not related either to age at diabetes onset or to HbA1c levels at the time of investigation. Significant though low direct correlations between negative emotional consequences score and diabetes duration $(r=0.138$, $\mathrm{p}<0.001)$ and between the PAID overall score and diabetes duration $(\mathrm{r}=0.119, \mathrm{p}=0.003)$ were observed.

\section{Discussion}

Similarly to the study by Miller \& Elasy (Miller \& Elasy, 2008), the factor analysis of our study confirmed a 2-factor solution of the PAID in a cohort of adolescent and emerging adult 
T1D patients: lack of confidence in self-care subscale (5 items) and negative emotional consequences subscale (15 items). The original scale was constructed as a single domain structure (Polonsky et al., 1995), however later other authors have found conflicting results, with some confirming the original single-factor structure (Welch et al., 1997; Huang et al, 2010), and others identifying multiple sub-dimensions (Snoek et al., 2000; Amsberg et al., 2008; Miller \& Elasy, 2008). Snoek (Snoek et al., 2000) identified 4 subdimensions: negative emotions (12 items of the PAID questionnaire), treatment problems ( 3 items), food-related problems ( 3 items), and lack of social support (2 items). Amsberg (Amsberg et al., 2008) identified 3 subdimentions: diabetesrelated emotional problems (15 items), treatment-related problems (2 items), and support-related problems (3 items). Miller and Elasy (Miller \& Elasy, 2008) identified 2 subdimentions: lack of confidence in self-care implementation ( 7 items) and negative emotional consequences of self-care implementation (13 items).

Principal findings of our study revealed that high overall diabetes distress score, suggesting clinical distress, was found in as much as $22.8 \%$ of young people with T1D, and it appreared to be higher in emerging adults compared to adolescents, regardless of diabetes control: lack of confidence in self-care, negative emotional consequences, as well as PAID overall score were more expressed in adut compared to adolescent males and negative emotional consequences, as well as PAID overall score were more prevalent in adult than in adolescent females with T1D. The overall diabetes distress in adolescent girls was found to be significantly more pronounced compared to adolescent boys. Similarly, in adult patients, females had higher negative emotional consequences aspect of diabetes distress compared to males.

The gender specific psychological impact of diabetes burden was also evident in our previous research on diabetes distress in adult T1D patients using Diabetes Distress Scale (Lašaitė et al., 2016): adult childhood-onset T1D females had higher regimen-related distress than adulthood-onset females; adult childhood-onset T1D females experienced higher diabetes distress 
(higher emotional burden, physician-related distress and total diabetes distress score) than childhood-onset males; adulthood-onset T1D females experienced higher physician-related distress, but lower regimen-related distress than males. Similarly, other authors have found high distress levels to be more prevalent among young adult females with T1D compared with males (Zoffmann et al., 2014).

It is possible that different associations between distress, depression and diabetes in males and females mirror different coping strategies that could underlie gender-specific differences (Eriksson et al., 2008). Females are more likely than males to perceive that support is available from network members (Barry et al., 2009; Kendler et al., 2005) and are more likely than males to have someone available to talk to when they are distressed (Matthews et al., 1999). One of the explanations for these gender differences has to do with the way that females and males are socialized. Females are socialized to be relationship-oriented or communal, and males are socialized to be self-oriented or agentic (Bem, 1974). Gender differences could also reflect different psychological and social challenges, potentially becoming stressors that young males and females experience at this stage of life when independent lifestyles are being established and adult roles assumed (Arnett, 2000; Graber, 2004).

In other studies, analysing wider age range, significantly higher diabetes distress was observed in younger than older adults, females more than males, those with no partner more than those with partner, and those with more complications than those with fewer or none (Fisher et al., 2015). Younger adults with T2D had significantly more problems with diabetes management and glycemic control, and reported higher general and diabetes-related distress than older adults with T2D (Hessler et al., 2010; Hessler et al., 2011; Simmons et al., 2013). Similar age differences were found in diabetes distress among T1D patients, suggesting that not only adolescents, but also younger adults with T1D, along with those patients with no partner, may require specialized, targeted interventions to address their unique personal and social needs (Fisher et al., 2015). 
Of our sample, $22.8 \%$ T1D patients (17.2\% of adolescent group and $27.9 \%$ of adult group) reported diabetes distress overall scores over the cut-off score of equal or higher than 40 on the PAID scale, suggesting clinical distress (Snoek et al., 2015). Other authors have found even higher prevalence of clinical distress in patients with diabetes. In the study by Schmitt et al. (Schmitt et al., 2015b) comparing properties of the two most commonly used tools for diabetes distress (PAID and Diabetes Distress Scale), $41.9 \%$ of a sample of 420 T1D patients and $46.6 \%$ of a sample of 208 type 2 diabetic patients reported diabetes distress scores, suggesting clinical distress. Of 2374 type 2 diabetic patients in another study (Pintaudi et al., 2015), 60.2\% had the PAID score, suggesting clinical distress. However, the samples of different studies are different regarding age of patients, diabetes duration, type of diabetes, other diabetes-related potential confounders such as diabetes education, self-management practice, other diseases, also psychological (especially emotional aspect) and socioeconomic status of patients, and other important factors. Each of these mentioned factors and many others could possibly have impact on overall diabetes-related distress level, as well as other possibly involved covariates.

Compared to patients with a PAID score lower than 40, those with clinical distress were more often female, living alone, had a lower level of education, a higher HbA1c levels, a greater perceived impact of hyperglycaemic and hypoglycaemic symptoms, a greater number of diabetes-related complications (Pintaudi et al., 2015). According to a recent systematic review (Hagger et al., 2016), around one third of adolescents with T1D experienced elevated diabetes distress and this was frequently associated with suboptimal glycemic control, low self-efficacy and reduced self-care. In our cohort, we did not find any significant association between diabetes distress and glycemic control at the time of investigation, even though $\mathrm{HbA1c}$ level was higher in adolescent girls compared to boys, although not reaching statistical significance. Only diabetes duration was significantly related to negative emotional consequences score and the PAID overall score in patients of our study. 
Fisher et al. (Fisher at al., 2012) found nonlinear relationship of diabetes-specific emotional distress with HbA1c, diet, self-efficacy, and physical activity with stronger relationships for lower levels of diabetes-specific distress. It was suggested that diabetes distress is not only burdensome itself, but also may impede the self-care behaviours of patients, thereby compromising glycemic control (Metsch et al., 1995).

Some studies suggest that glycaemic control is affected more strongly by diabetes distress than by depression, both in type 1 and type 2 diabetes (Fisher et al., 2010; Strandberger et al., 2014; Reddy et al., 2013). Moreover, findings of two independent studies showed that the association between depressive symptoms and glycaemic control was explained by diabetes distress (van Bastelaar et al., 2010; Schmitt et al., 2015a). High levels of diabetes distress are associated with worse not only clinical but also psychosocial outcomes and should be considered as a key patient-centered indicator (Pintaudi et al., 2015). On the other hand, it was suggested that diabetes distress could progress to depression (Fisher et al., 2014; Holt et al., 2014). Regression analyses showed that depression is a predictor for 12-month diabetes distress and vice versa suggesting a bidirectional association (Snoek et al., 2012).

Similar to our study, in some other studies (Joensen et al, 2013; Strandberg et al., 2014) sifnificant relationship between diabetes distress and glycemic control in T1D patients was not found. Absence of such a relationship in adults with T1D, in conjunction with its presence in adults with T2D (Fisher et al., 2012), might indicate that emotional problems have different implications for persons with type 1 and type 2 diabetes (Strandberg et al., 2014). For example, a recent qualitative study reported that diabetes distress was common among T1D patients and identified several sources likely to be unique to T1D, including a sense of self-consciousness about diabetes, concern about being misidentified as having T2D, day-to-day management distress, healthcare system struggles, fears about complications and the future, and concerns about pregnancy (Balfe et al., 2013). A recent study (Fisher et al., 2015) indicated a far lager number of 
sources of diabetes distress among adults with T1D than among those with type 2 diabetes: powerlessness, negative social perceptions, physical distress, friend/family distress, hypoglycemia distress, diabetes management distress, eating distress. Thus, while some sources of diabetes distress among adults with T1D overlap with those reported by T2D patients, T1D patients experience distress in coherent patterns that are more numerous and qualitatively different from T2D patients (Fisher et al., 2015).

There are some limitations of the study that must be mentioned. First, the crosssectional design of the study does not allow for cause-effect inferences between diabetes distress and diabetes-related aspects (such as HbAlc level, diabetes duration, age at T1D onset). Second, there are potential confounders that were not controlled for, including diabetes knowledge, selfmanagement practices, medication adherence, emotional state (paying special attention to depression) and social support.

In conclusion, high overall diabetes distress score, suggesting clinical distress, was found in as much as $22.8 \%$ of young people with T1D, and it appreared to be greater in emerging adults compared to adolescents. The overall diabetes distress in adolescent girls was found to be significantly more pronounced compared to adolescent boys. Similarly, in emerging adult patients, females had higher negative emotional consequences aspect of diabetes distress compared to males. Diabetes distress was`directly related to the disease duration, but not glycemic control. A 2-factor solution of the PAID in a cohort of adolescent and emerging adult T1D patients was confirmed.

Our principal findings show that patients with T1D have greater burden of diabetes distress in emerging adulthood than in adolescence. These findings are exploratory and need to be examined further, but they add to growing evidence suggesting the importance of addressing diabetes distress in clinical care for young patients with T1D and the necessity of wider picture beyond the physical manifestation of diabetes to be taken into consideration (Fisher et al., 2014). 
Provision of psychological support, psychotherapeutic interventions, teaching of stress-management techniques, diabetes education, as well as modification of diabetes distress by the external environment, including society, family, health care services and peer support groups should be accompanied by prospective assessment of its efficacy.

\section{Acknowledgments}

This study was supported by a grant of Lithuanian Research Council Lithuanian-Swiss program „Research and Development“, CH-3-ŠSMM-01/09 and the Federal Department of Foreign Affairs of Switzerland.

\section{References:}

Amsberg S, Wredling R, Lins PE, Adamson U, Johansson UB. The psychometric properties of the Swedish version of the Problem Areas in Diabetes Scale (Swe-PAID-20): scale development. Intern J Nurs Stud 2008; 45(9): 1319-1328.

Arnett JJ. Emerging adulthood:A theory of development from the late teens through the twenties. Am Psychol 2000; 55: 469-480.

Arnett JJ. Socialization in emerging adulthood: From the family to the wider world, from socialization to self-socializtion. In: Grusec JE, Hastings PD, editors. Handbook of socialization: Theory and research. Guilford Press; New York: 2007. P. 208-237. 
Balfe M, Doyle F, Smith D, Screenan S, Brugha R, Hevey D, Conroy R. What's distressing about having type 1 diabetes? A qualitative study of young adults' perspectives. BMC Endocrine Disorders 2013; 13: 13-25.

Barry CM, Madsen Sd, Nelson LJ, Carroll JS, Bedger S. Friendship and romantic relationship qualities in emergin adulthood: Differential associations with identity development and achieved adulthood criteria. Journal of Adult Development 2009; 16: 209-222.

Bem SL. The measurement of psychological androginy. Journal of Consulting and Clinical Psychology 1974; 42: 155-162.

Byrne DG, Davenport SC, Mazanov J. Profiles of adolescent stress: The development of the Adolescent Stress Questionnaire (ASQ). Journal of Adolescence 2007; 30: 393-416.

de Ridder D, Geenen R, Kuijer R, van Middendorp H. Psychological adjustment to chronic disease. Lancet 2008; 372: 246-255.

Delamater AM, Kurtz SM, Bubb J, White NH, Santiago JV. Stress and coping in relation to metabolic control of adolescents with type 1 diabetes mellitus. J Dev Behav Pediatr 1987; 8: 136140. 
Eriksson AK, Ekbom A, Granath F, Hilding A, Efendic S, Ostenson CG. Psychological distress and risk of prie-diabetes and type 2 diabetes in a prospective study of Swedish middle-aged men and women. Diabetic Med 2008; 25(7): 831-842.

Fisher L, Skaff MM, Mullan JT, Arean P, Mohr D, Masharani U, Glasgow R, Laurencin G. Clinical depression versus distress among patients with type 2 diabetes: not just a question of semantics. Diabetes Care 2007; 30(3): 542-548.

Fisher L, Glasgow RE, Mullan JT, Skaff MM, Polonsky WH. Development of a brief diabetes distress screening instrument. Annals of Family Medicine 2008; 6(3): 246-252.

Fisher L, Mullan JT, Arean P, Glasgow RE, Hessler D, Mashsrani U. Diabetes distress but not clinical depression or depressive symptoms is associated with glycemic control in both crosssectional and longitudinal analyses. Diabetes Care 2010; 33: 23-28.

Fisher L, Hessler D, Polonsky W, Mullan J. When is diabetes distress clinically meaningful. Establishing cut points for the diabetes distress scale. Diabetes Care 2012; 35: 259-264.

Fisher L, Gonzalez JS, Polonsky WH. The confusing tale of depression and distress in patients with diabetes: a call for greater clarity and precision. Diabet Med 2014; 31: 764-772.

Fisher L, Polonsky WH, Hessler DM, Masharani U, Blumer I, Peters AL, Stryker LA, Bowyer V. Understanding the sources of diabetes distress in adults with type 1 diabetes. J Diabet Compl 2015; 29: $572-577$. 
Gåfvels C, Lithner F, Börjeson B. Living with diabetes: relationship to gender, duration and complications. A survey in Northern Sweden. Diabetes Med 1993; 10(8): 768-773.

Gendelman N, Snell-Bergeon JK, McFann K, Kinney G, Wadwa PR, Bishop F, Rewers M, Maahs DM. Prevalence and correlates of depression in individuals with and without type 1 diabetes. Diabetes Care 2009; 32: 575-579.

Gortmaker SL, Walker DK, Weitzman M, Sobol AM. Chronic conditions, socioeconomic risks, and behavioral problems in children and adolescents. Pediatrics 1990; 85: 267-276.

Graber JA. Internalizing problems during adolescence. In: The handbook of adolescent psychology. Volume 2. Edited by Lerner RM, Steinberg L. New York: John Wiley and Sous, Inc, 2004.

Hagger V, Hendrieckx C, Sturt J, Skinner TC, Speight J. Diabetes distress among adolescents with type 1 diabetes: a systematic review. Curr Diab Rep 2016; 16(1): 9. doi: 10. 1007/s11892-0150694-2.

Helgeson VS, Escobar O, Siminerio L, Becker D. Relation of stressful life events to metabolic control among adolescents with diabetes: five year longitudinal study. Health Psychol 2010; 29(2): 153-159.

Helgeson VS, Reynolds KA, Siminerio LM, Becker DJ, Escobar O. Cognitive adaptation theory as a predictor of adjustment to emerging adulthood for youth with and without type 1 diabetes. $J$ Psychosom Res 2014; 77(6): 484-491. 
Hermanns N, Kulzer B, Krichbaum M, Kubiak T, Haak T. How to screen for depression and emotional problems in patients with diabetes: comparison of screening characteristics of depression questionnaires, measurement of diabetes-specific emotional problems and Standard clinical assessment. Diabetologia 2006; 49(3): 469-477.

Hessler DM, Fisher L, Mullan JT, Masharani U. Age differences in adult type 2 diabetes management and glycemic control. Diabetes 2010; 59(Suppl. 1): 1435.

Hessler DM, Fisher L, Mullan JT, Glasgow RE, Masharani U. Patient age: A neglected factor when considering disease management in adult with type 2 diabetes. Patient Education and Counceling 2011; 85: 154-159.

Holmbeck GN, Friedman D, Abad M, Jandasek B. Development and psychopatology in adolescence. In: Behavioral and emotional disorders in adolescents. Edited by Wolfe DA, Mask EJ. New York: The Guilford Press, 2006, pp 21-55.

Holt RI, de Groot M, Lucki I, Hunter CM, Sartorius N, Golden SH. NIDDK International Conference Report on Diabetes and Depression: current understanding and future directions. Diabetes Care 2014; 37: 2067-2077.

Huang MF, Courtney M, Edwards H, McDowell J. Validation of the chinese version of the problem areas in diabetes (PAID-C) Scale. Diabetes Care 2010; 33: 38-40.

Joensen LE, Tapager I, Willaing I. Diabetes distress in type 1 diabetes - a new measurement fit for purpose. Diabet Med 2013; 30: 1132-1139. 
Johnson J, Cohen P, Gould M. Kasen S, Brown J, Brook J. Childhood adversities, interpersonal difficulties, and risk for suicide attempts during late adolescence and early adulthood. Archives of General Psychiatry 2002; 59: 741-749.

Jones JM, Lawson ML, Daneman D, Olmstead MP, Rodin G. Eating disorders in adolescent females with and without type 1 diabetes: Cross-sectional study. Brit Med J 2000; 320: 1563-1566.

Kendler KS, Myers J, Prescott CA. Sex differences in the relationship between social support and risk for major depression: A longitudinal study of opposite-sex twin pairs. The American Journal of Psychiatry 2005; 162: 250-256.

Kessler RC, Mickelson KD, Walters EE, Zhao S, Hamilton L. Age and sepression in the MIDUS survey. How healthy we are? In: Brim OG, Ryff CD, Kessler RC, editors. A national study of wellbeing at midlife. The University of Chicago Press, IL: 2004. P. 227-251.

Lašaitė L, Ostrauskas R, Žalinkevičius R, Jurgevičienė N, Radzevičienė L. Diabetes Distress in Adult Type 1 Diabetes Mellitus Men and Women with Disease Onset in Childhood and in Adulthood. $J$ Diabet Compl 2016; 30: 133-137.

Luecken LJ, Gress JL. Early adversity and resilience in emerging adulthood. In: Reich JW, Zautra AJ, Hall J, editors. Handbook of adult resilience. Guilford Press; New York: 2010. P. 238-257.

Luyckx K, Seiffge-Krenke I. Continuity and change in glycemic control trajectories from adolescence to emerging adulthood. Diabetes Care 2009, 32(5): 797-801. 
Mann NP, Johnston DI. Total glycosylated haemoglobin levels (HbA1) in diabetic children. Arch Dis Child 1982; 57: 434-437.

Matthews S, Manor O, Power C. Social inequalities in health: Are there gender differences? Social Science and Medicine 1999; 48: 49-60.

Metsch J, Tillil H, Köbberling J, Sartory G. On the relationship among psychological distress, diabetes-related health behaviour, and level of glycosylated hemoglobin in type 1 diabetes. $J$ Behav Med 1995; 2: 104-117.

Miller ST, Elasy TA. Psychometric evaluation of the Problem Areas in Diabetes (PAID) survey in Southern, rural African women with Type 2 diabetes. BMC Public Health 2008; 8: 70-77).

Northam E, Mathews L, Anderson P, Camerson F, Werther G. Psychiatric morbidity and health outcome in type 1 diabetes - perspectives from a prospective longitudinal study. Diabet Med 2005; 22: $152-157$.

Pintaudi B, Lucisano G, Gentile S, Bulotta A, Skovlund SE, Vespasiani G, Rossi MC, Nicolucci A, BENCH-D Study Group. Correlates of diabetes-related distress in type 2 diabetes: Findings from the benchmarking network for clinical and humanistic outcomes in diabetes (BENCH-D) study. $J$ Psychosom Res 2015; 79(5): 348-354.

Polonsky WH, Anderson BJ, Lohrer PA, Welch G, Jacobson AM, Aponte JE, et al. Assessment of diabetes-related distress. Diabetes Care 1995; 18(6): 754-760. 
Reddy J, Wilhelm K, Campbell L. Putting PAID to diabetes-related distress: the potential utility of the problem areas in diabetes (PAID) scale in patients with diabetes. Psychosomatics 2013; 54: 4451.

Rubin RR, Peyrot M. Quality of life and diabetes. Diabetes Metab Res Rev 1999; 15: 205-218.

Rydall AC, Rodin GM, Olmsted MP, Devenyi RG, Daneman D. Disordered eating behavior and microvascular complications in young women with insulin-dependent diabetes mellitus. New Engl J Med 1997; 336(26): 1849-1854.

Schmitt A, Reimer A, Kulzer B, Haak T, Gahr A, Hermanns N. Negative association between depression and diabetes control only when accompanied by diabetes-specific distress. J Behavioral Med 2015; 38(3): 556-564.

Schmitt A, Reimer A, Kulzer B, Haak T, Ehrmann D, Hermanns N. How to assess diabetes distress: comparison of the Problem Areas in Diabetes Scale (PAID) and the Diabetes Distress Scale (DDS). Diabet Med 2015; doi: 10.1111/dme.12887. [Epub ahead of print].

Schultz CJ, Konopelska-Bahu T, Dalton RN, Carroll TA, Stratton I, Gale EAM, Neil A, Dunger DB. Microalbinuria prevalence varies with age, sex, and puberty in children with type I diabetes followed from diagnosis in a longitudinal study. Diabetes Care 1999; 22: 495-502. 
Simmons JH, Chen V, Miller KM, McGill JB, Bergenstal RM, Goland RS, et al. Differences in the management of type 1 diabetes among adults under excellent control compared with those under poor control in the T1D Exchange Clinic Registry. Diabetes Care 2013; 36: 3573-3577.

Snoek FJ, Pouwer F, Welch GW, Polonsky WH. Diabetes-related emotional distress in Dutch and US diabetic patients: cross-cultural validity of the problem areas in diabetes scale. Diabetes Care 2000; 23(9): 1305-1309.

Snoek FJ, Kersch NY, Eldrup E, Harman-Boehm I, Hermanns N, Kokoszka A, Matthews DR, McGuire BE, Pibernik-Okanovic M, Singer J, de Wit M, Skovlund SE. Monitoring of Individual Needs in Diabetes (MIND)-2: follow-up data from the cross-national Diabetes Attitudes, Wishes, and Needs (DAWN)MIND Study. Diabetes Care 2012; 35: 2128-2132.

Snoek F, Bremmer MA, Hermanns N. Constructs of depression and distress in diabetes: time for an appraisal. Lancet Diabetes Endocrinol 2015: 3: 450-460.

Stone AA, Schwartz JE, Broderick JE, Deaton A. A snapshot at the age distribution of psychological well-being in the United States. PNAS Proceedings of the National Academy of Sciences of the United States of America. 2010; 107: 9985-9990.

Strandberg RB, Graue M, Wentzel-Larsen M, Peyrot M, Rokne B. Relationships of diabetesspecific emotional distress, depression, anxiety, and overall well-being with HbA1c in adult persons with type 1 diabetes. J Psychosomc Res 2014; 77: 174-179. 
van Bastelaar KM, Pouwer F, Geelhoed-Duijvestijn PH, Tack CJ, bazelmans E, Beekman AT, Heine RJ, Snoek FJ. Diabetes-specific emotional distress mediates the association between depressive symptoms and glycaemic control in Type 1 and Type 2 diabetes. Diabet Med 2010; 27: 798-803.

Welch GW, Jacobson AM, Polonsky WH. The problem Areas in Diabetes Scale. An evaluation of its clinical utility. Diabetes Care 1997: 20: 760-766.

Wilkinson A, Whitehead L, RitchieI. Factors influencing the ability to self-manage diabetes for adults living with type 1 or 2 diabetes. Int J Nurs Stud 2014; 51: 111-122.

Wolpert HA, Anderson BJ. Young adults with diabetes: need for a new treatment paradigm. Diabetes Care 2001; 24: 1513-1514.

World Health Organization, United Nations Population Fund, UNICEF. The Reproductive health of adolescents: a strategy for action: a joint WHO/UNFPA/UNICEF statement. World Health Organization, Geneva, 1989:1-18.

Zoffmann V, Vistisen D, Due-Christensen M. A cross-sectional study of glycaemic control, complications and psychosocial functioning among 18- to 35-year-old adults with type 1 diabetes. Diabet Med 2014; 31(4): 493-499. 
Table 1. Descriptive information of adolescent and emerging adult males and females with type 1 diabetes

\begin{tabular}{|c|c|c|c|}
\hline Categories & & Adolescents & Adults \\
\hline \multirow{3}{*}{$\begin{array}{l}\text { Participants of the study, } \\
\mathrm{n}(\%)\end{array}$} & Males & $123(48.2)$ & $135(47.7)$ \\
\hline & Females & $132(51.8)$ & $148(52.3)$ \\
\hline & Total & $255(47.4)$ & $283(52.6)$ \\
\hline \multirow{2}{*}{$\begin{array}{l}\text { Education, } \\
\text { n (\%) }\end{array}$} & Lower than university & & $97(34.3)$ \\
\hline & $\begin{array}{l}\text { Graduated university or } \\
\text { still studying }\end{array}$ & & $141(65.7)$ \\
\hline \multirow{2}{*}{$\begin{array}{l}\text { Employment, } \\
\text { n (\%) }\end{array}$} & Employed & & $116(40.9)$ \\
\hline & Unemployed or studying & & $122(59.1)$ \\
\hline \multirow{3}{*}{$\begin{array}{l}\text { Matrital status, } \\
\text { n (\%) }\end{array}$} & Single & & $215(75.9)$ \\
\hline & Married or cohabiting & & $62(21.9)$ \\
\hline & Divorced or separated & & $6(2.2)$ \\
\hline \multirow{2}{*}{$\begin{array}{l}\text { Insulin delivery method, } \\
\mathrm{n}(\%)\end{array}$} & Insulin pump & $84(32.9)$ & $51(18.1)$ \\
\hline & Multiple daily injections & $171(67.1)$ & $232(81.9)$ \\
\hline
\end{tabular}


Table 2. Comparison of age, age at diabetes onset, diabetes duration, $\mathrm{HbA1c}$ level and diabetes distress (Problem Areas in Diabetes (PAID) scale overall score and subscales) in adolescent and emerging adult males and females with type 1 diabetes

\begin{tabular}{|c|c|c|c|c|c|c|}
\hline \multirow[t]{2}{*}{ Categories } & \multirow[t]{2}{*}{ Gender } & \multicolumn{2}{|c|}{ Adolescents $(\mathrm{n}=255)$} & \multicolumn{2}{|c|}{ Adults $(n=283)$} & \multirow[t]{2}{*}{$p$} \\
\hline & & Median & $\begin{array}{l}25-75 \\
\text { percentile }\end{array}$ & Median & $\begin{array}{l}25-75 \\
\text { percentile }\end{array}$ & \\
\hline \multirow[t]{2}{*}{ Age, years } & Males & 16.5 & $15.0-17.0$ & 22.0 & $21.0-24.0$ & $<0.001$ \\
\hline & Females & 17.0 & $16.0-17.0$ & 23.0 & $20.0-24.0$ & $<0.001$ \\
\hline \multirow[t]{2}{*}{ Age at T1D onset, years } & Males & 12.0 & $7.0-14.0$ & 14.0 & $10.0-19.0$ & $<0.001$ \\
\hline & Females & 10.0 & $7.0-13.0$ & 12.0 & $9.0-17.0$ & $<0.001$ \\
\hline \multirow[t]{2}{*}{ T1D duration, years } & Males & 4.0 & $2.0-10.0$ & 8.0 & $3.0-12.0$ & 0.003 \\
\hline & Females & 6.0 & $3.0-10.0$ & 10.0 & $4.0-13.0$ & $<0.001$ \\
\hline \multirow[t]{2}{*}{$\mathrm{HbA} 1 \mathrm{c}, \%$} & Males & 8.2 & $7.04-9.27$ & 8.36 & $7.0-10.21$ & 0.0991 \\
\hline & Females & 9.05 & $7.59-10.38$ & 8.38 & $7.14-10.54$ & 0.095 \\
\hline \multirow[t]{2}{*}{ PAID Overall score* } & Males & $11.25^{* *}$ & $2.81-27.19$ & 18.75 & $8.75-35.62$ & 0.002 \\
\hline & Females & 20.0 & $12.5-36.25$ & 25.0 & $11.25-41.25$ & 0.016 \\
\hline \multirow{2}{*}{$\begin{array}{l}\text { PAID Lack of Confidence } \\
\text { in Self-Care Subscale* }\end{array}$} & Males & $3.0^{* *}$ & $0.0-8.0$ & 6.0 & $2.0-11.0$ & 0.002 \\
\hline & Females & 6.0 & $3.0-10.0$ & 7.0 & $2.25-13.0$ & 0.153 \\
\hline \multirow{2}{*}{$\begin{array}{l}\text { PAID Negative Emotional } \\
\text { Consequences Subscale* }\end{array}$} & Males & $6.0 * *$ & $1.0-14,75$ & $10.0^{* *}$ & $4.0-18.0$ & 0.004 \\
\hline & Females & 10.0 & $5.0-18.0$ & 13.0 & $6.0-21.0$ & 0.005 \\
\hline
\end{tabular}

PAID - Problem Areas in Diabetes;

* a higher score indicates a higher distress level.

** $p<0.05$ between males and females within the same age group. 
Table 3. Pearson correlation coefficients between diabetes-related distress and age at onset of diabetes, diabetes duration and $\mathrm{HbA} 1 \mathrm{c}$ level

\begin{tabular}{|l|l|l|l|l|l|l|}
\hline & & $\begin{array}{l}\text { Lack of } \\
\text { confidence } \\
\text { in self-care }\end{array}$ & $\begin{array}{l}\text { Emotional } \\
\text { consequences }\end{array}$ & $\begin{array}{l}\text { Age at } \\
\text { T1D } \\
\text { onset }\end{array}$ & $\begin{array}{l}\text { T1D } \\
\text { duration }\end{array}$ & $\begin{array}{l}\text { HbA1c } \\
\text { level }\end{array}$ \\
\hline $\begin{array}{l}\text { Lack of } \\
\text { confidence in } \\
\text { self-care }\end{array}$ & $r$ & - & $0.857^{*}$ & 0.018 & 0.064 & 0.059 \\
\hline $\begin{array}{l}\text { Emotional } \\
\text { consequences }\end{array}$ & $r$ & $0.857^{*}$ & - & -0.051 & $0.138^{*}$ & 0.045 \\
\hline $\begin{array}{l}\text { PAID Overall } \\
\text { score }\end{array}$ & $r$ & $0.941^{*}$ & $0.981^{*}$ & -0.027 & $0.119^{* *}$ & 0.052 \\
\hline
\end{tabular}

${ }^{*} \mathrm{p}<0.001$

$* * p<0.05$ 